\title{
Nutrient Enrichment and Saline Conditions Decreases Growth and Photosynthesis of the Mangrove Heritiera littoralis Dryand
}

\author{
Mwita M. Mangora \\ Institute of Marine Sciences, University of Dar es Salaam, Zanzibar, Tanzania \\ Email:mmangora@yahoo.com, mangora@ims.udsm.ac.tz
}

Received 13 March 2016; accepted 18 April 2016; published 21 April 2016

Copyright @ 2016 by author and Scientific Research Publishing Inc.

This work is licensed under the Creative Commons Attribution International License (CC BY). http://creativecommons.org/licenses/by/4.0/

(c) () Open Access

\section{Abstract}

Inundation associated with flooding and sea level rise is predicted to have major impacts on survival, growth and productivity of mangroves. A manipulative mesocosm experiment was conducted to assess whether nutrient enrichment enhances growth and photosynthesis of waterlogged and salinity stressed seedlings of the mangrove Heritiera littoralis Dryand. Seedlings were fertilized with a three-component granular farm NPK (Nitrogen-Phosphorous-Potassium, 20:20:20) at varied loads under waterlogging with four levels of salinity. Growth was assessed through biomass accumulation, and photosynthesis through photosynthetic quantum yield and leaf Chl content. When seedlings were exposed to both nutrient enrichment and increased salinity, a significant shift of biomass to roots was observed. Seedlings had low value of $\mathrm{Chl} a / b$ ratio and photosynthetic distraction resulting in mortality was high in the highest salinity and nutrient levels. These results are useful in explaining failure of regeneration in natural stands of riverine and freshwater bound mangroves following unprecedented flooding events that accrue land based nutrient loads into estuaries and deltas.

\section{Keywords}

Heritiera littoralis, Mangrove Seedlings, Nutrient Enrichment, Salinity, Waterlogging

\section{Introduction}

Mangroves inhabit the land-sea interface where tidal inundation and salinity gradients are a natural phenomenon. Nonetheless, inundations and salinity are among the problems that confront mangroves when their optimal levels are exceeded, often causing a proliferation of anaerobic microbes and draining of essential nutrients [1]-[3]. 
Nutrient additions are reported to enhance growth, but many in-situ and ex-situ experiments have indicated mixed results [1] [2]. The effect of disrupted inundation, salinity gradients and deficiency of nutrients is exacerbated by other edaphic factors like sedimentation and a number of atmospheric factors like temperature, humidity, and light [2] [4], affecting mangrove ecological and physiological traits [5] [6].

In nature, many environmental effects are commonly interactive [7], such that species responses are complicated when the impact of one factor is either strengthened or weakened by the variation of another factor; or the combined influence of two or three stressors pushes an individual or population beyond a critical threshold that would not be reached as a result of a single stress factor [8]. For example, [5] reported that a five-day continuous waterlogging did not affect photosynthetic performance of Avicennia marina trees in low salinities. On the other hand, [9] found that photosynthesis and survival rates of A. marina, Bruguiera gymnorrhiza and Heritiera littoralis declined with increasing salinity and prolonged submergence. [10] observed that, although $B$. sexangula and Rhizophora mangle had contrasting strategies to cope with stressful salinity and light, growth was equally favoured by low salinity and light. Another observation by [4] indicated that the interactive effects of salinity and light in the greenhouse were comparable to the field observation where photosynthesis and growth increased more with light and low salinity.

Reported enhanced growth in mangroves due to availability of nutrients [1] [2] [11]-[17], favours more above-ground shoot at the expense of below-ground root biomass [18]. [3] compared three mangrove species, Laguncularia racemosa, A. germinans and Rhizophora mangle, and observed that frequent and prolonged flooding with constant nutrient and salinity had a species specific effect on growth, whereby shoot biomass was enhanced than roots for only L. racemosa. [19] observed that although nutrient enrichment enhanced growth rates, it increased vulnerability of mangroves to environmental stresses such as salinity due to distortion in ecophysiological traits like plant-water relations. They observed high mortality of mangroves where nutrient enrichment and high salinity were coincident with low precipitation. With regard to sedimentation, [20] reported that photosynthesis and growth of mangroves were enhanced where low sedimentation coincided with high nutrients. In contrast, [16] observed that nutrient enrichment significantly enhanced growth and photosynthesis at the high than low sedimentation sites.

These contrasting observations continue to limit our precise understanding of the factors controlling successive regeneration especially in degraded mangrove forests at local scales as suggested by [7] [14]. In this study, a mesocosm experiment was set to evaluate whether nutrient enrichment would influence growth and photosynthesis of waterlogged and salinity stressed seedlings of the $H$. littoralis which is a common riverine species where freshwater influence is dominant. It was hypothesized that, nutrient enrichment would counteract the effect of prolonged waterlogging with increasing salinity to enhance growth and photosynthesis. Measurement of photosynthetic quantum yield and Chl content was completed to evaluate the photosynthetic functioning and analysis of biomass accumulation patterns to determine the growth articulation.

\section{Materials and Methods}

\subsection{Mangrove Seedlings}

Seeds of $H$. littoralis and forest sediment were collected from a natural mangrove stand in Ruvu River Estuary on the mainland coast of Tanzania and shipped to the experimental site at Buyu, along the west coast of Zanzibar Island. Pore water samples collected from sites where propagating plant materials and forest sediment were collected from indicated that salinity ranges from freshwater to 15 with a decreasing trend upstream. Before sowing, seeds were sorted for quality and evenness, selecting those with relatively similar dimensions, averaging $4 \mathrm{~cm}$ in thickness. Seeds were directly sown without pre-treatment (loosely covered by sediment and embryo facing down) on a nursery made of a 3:1 mixture of the forest sediment and washed beach sand, under an open air shaded nursery with average light of $325 \pm 40 \mu \mathrm{mol}$ photon $\mathrm{m}^{-2} \cdot \mathrm{s}^{-1}$ mimicking the field canopy shade at midday. The nursery was watered twice a day (morning and evening) with freshwater from a nearby natural well. First germinates were observed after approximately 30 days. These were allowed to grow for three months. Each seedling was then transferred into a 10 litre plastic bucket $(28 \mathrm{~cm}$ height $\times 25 \mathrm{~cm}$ diameter, with 10 holes of 1 $\mathrm{cm}$ diameter made on the base). The buckets were filled halfway with the same mixture of forest sediment and washed beach sand described above.

Seedlings in the buckets were watered twice a day using freshwater from the same nearby natural well and allowed to grow for another three months. On a monthly basis during this growing period, half of the potting 
sediment mixture in each bucket was carefully removed avoiding disturbance to the root system and replaced with fresh sediment mixture to maintain natural fertility. Before the mesocosm experiment described below, a sample of five seedlings was carefully uprooted, rinsed in freshwater and divided into shoots (stems and leaves) and roots, and weights determined before and after oven drying.

\subsection{Mesocosm Experiment}

Tanks of $100 \mathrm{~cm}$ diameter $\times 60 \mathrm{~cm}$ height were used for waterlogging, arranged in three replicates (Figure 1) under the same shade described above. For each tank, ten buckets were placed, each with one seedling. Granular farm NPK (20:20:20) was used to fertilize the seedlings in four treatments of no fertilizer (control), $2 \mathrm{~g}, 5 \mathrm{~g}$ and $10 \mathrm{~g}$. The fertilizer was added by evenly spreading the granules on top of the potting sediment in each bucket containing a seedling. A layer of $1 \mathrm{~cm}$ of washed beach sand was then spread on to cover the sediment and fertilizer from being washed away when filling in the tanks for waterlogging.

The tanks were filled with water of different salinity to a level of $10 \mathrm{~cm}$ of the seedling stem above the sediment. All the shoots remained above water. Four salinity levels were applied as ratios of freshwater to seawater, i.e. 1:0 is $100 \%$ freshwater (SW0), 2:1 is $33 \%$ seawater (SW33), 1:2 is $66 \%$ seawater (SW66) and 0:1 is $100 \%$ seawater (SW100). Continuous waterlogging lasted 14 days at which $80 \%$ of the seedlings were surviving in SW0 and only 30\% in SW33, and 10\% in SW66 and SW100 with the lowest photosynthetic signals to support survival.

\subsection{Biomass}

At the end of experiment, all surviving seedlings were harvested and rinsed in freshwater, separated into shoots (stem and leaves) and roots and their weights determined before and after oven drying at $60^{\circ} \mathrm{C}$ to determine biomass ratios. Root to shoot ratio was determined as the ratio of root (below-ground) to shoot (above-ground) mass ( $\mathrm{g} \mathrm{g}^{-1}=$ dimensionless).

\subsection{Photosynthesis and Chlorophyll Content}

Using a DIVING-PAM fluorometer (Heinz Walz GmbH, Effeltrich, Germany), point measurements of photo-

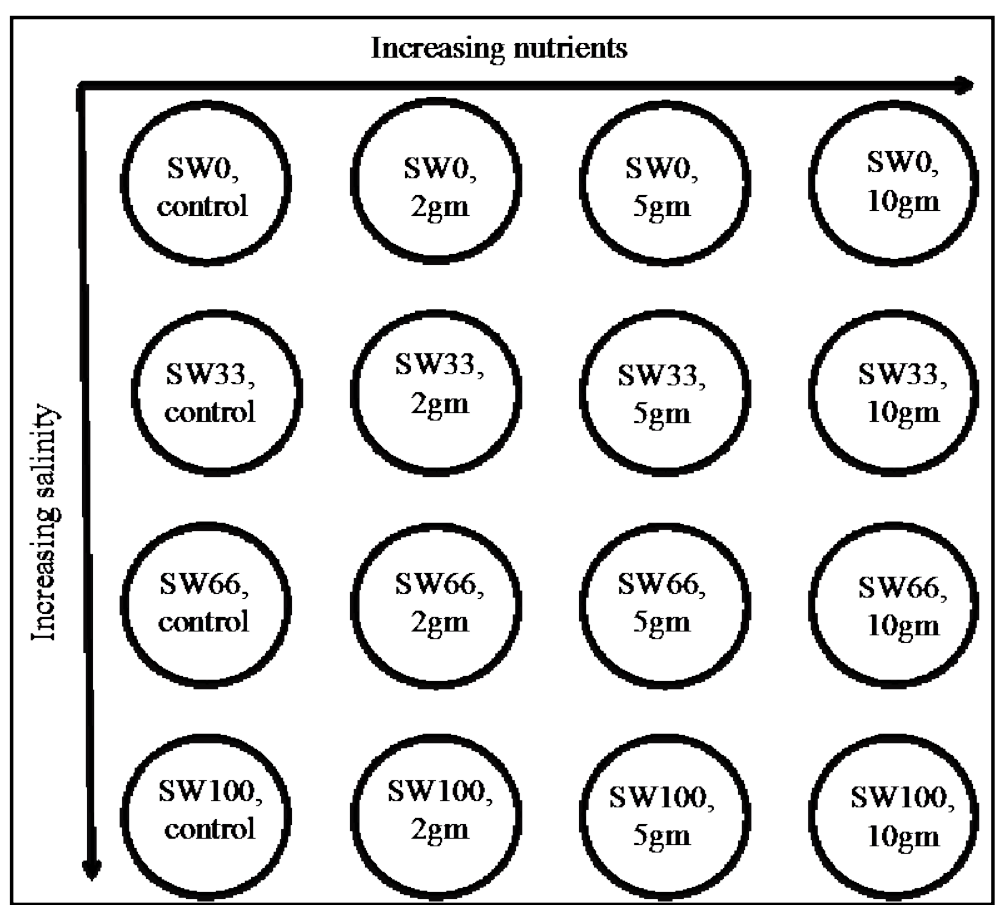

Figure 1. Arrangement of treatment tanks, indicating combinations of salinity and nutrient levels. Ten seedlings were placed in each tank in three replicates. 
chemical yield $(Y)$ were taken daily for the duration of waterlogging. Measurements were taken on five youngest, fully expanded leaves (usually on and below the penultimate leaf pair on a twig) between midmorning and midday when maximum photosynthesis is expected. All measurements were taken on the lamina, midway between the base and the tip of leaves. PAM fluorometer automatically calculates the $Y$ as the quantum yield of photosystem II (PSII) (also known as Genty-parameter) [21]:

$$
Y=\left(\Delta F / F m^{\prime}\right) / 1000
$$

where $F$ is the steady state photosynthetic yield measured briefly before the saturating light pulse and $F m^{\prime}$ is the maximal photosynthetic yield measured during the saturating light pulse.

On the last photosynthesis measurement, measured leaf samples were harvested from each seedling and quickly processed for extraction and analysis of Chl content. One g of fresh leaf tissues was ground and homogenized with a mortar and pestle in chilled $10 \mathrm{ml}$ of $100 \%$ acetone away from light. The homogenate was centrifuged for $10 \mathrm{~min}$ at $3000 \mathrm{rpm}$ in a Jouan C-312 centrifuge (Jouan Inc., Saint Mazaire, France). The supernatants were collected for photometric measurements of the absorbance at wavelengths of $661.6 \mathrm{~nm}$ and 644.8 $\mathrm{nm}$ for Chl $a$ and $b$ respectively using a SHIMADZU UV-1601 UV-VIS Spectrophotometer (SHIMADZU Corporation, Kyoto, Japan). Concentrations of Chl $a, b$ and total Chl $(a+b)$ in $\mu \mathrm{g} \cdot \mathrm{ml}^{-1}$ pigment extract solution were calculated using the equations by [22] as follows:

Concentration of Chl $a$ :

$$
\begin{aligned}
& \mathrm{C} a=11.24 \times \mathrm{A}_{661.6}-2.04 \times \mathrm{A}_{644.8} \\
& \mathrm{C} b=20.13 \times \mathrm{A}_{644.8}-4.19 \times \mathrm{A}_{661.6} \\
& \mathrm{C} a+b=7.05 \times \mathrm{A}_{661.6}+18.09 \times \mathrm{A}_{644.8}
\end{aligned}
$$

Concentration of Chl $b$ :

where $\mathrm{A}$ is the measured absorbance value at the specified wavelength.

\subsection{Statistical Analysis}

Mean values of biomass and photosynthesis data were computed and used for statistical analysis. Species and waterlogging were the same throughout the experiment, and therefore there were two main effects of salinity and nutrients on biomass and photosynthesis in three replicates. Analysis of Variance (ANOVA) with F-tests, test of homogeneity of variances and post-hoc tests were appropriately employed for statistical tests at significance levels of $P \leq 0.05$ for biomass and photosynthetic yield.

\section{Results}

\subsection{Biomass Accumulation and Allocation}

Partitioning of biomass was more sensitive to salinity. There was a significant $(P<0.01)$ shift of biomass to roots with increased salinity than nutrient enrichment (Table 1). Elevated salinity counteracted shoot formation in seedlings enriched with nutrient.

\subsection{Photosynthetic Yield}

The effect of different loads of nutrient enrichment with different salinities in prolonged waterlogging exerted significant variation on photosynthetic yield (Table 2). Nutrient enrichment in freshwater (SW0) did not affect photosynthesis of seedlings (Figure 2(a)). In SW33, nutrient enrichment exerted more stress than the interacting

Table 1. Root to shoot ratios (means $\pm S D, n=30$ ) in response to various levels of nutrient enrichment in different salinities over a 14 day waterlogging.

\begin{tabular}{ccccc}
\hline \multirow{2}{*}{ NPK nutrient load } & \multicolumn{3}{c}{ Salinity } & SW100 \\
\cline { 2 - 5 } & SW0 & SW33 & SW66 & $0.38 \pm 0.07$ \\
Control & $0.24 \pm 0.05$ & $0.21 \pm 0.04$ & $0.37 \pm 0.09$ & $0.28 \pm 0.04$ \\
$2 \mathrm{~g}$ & $0.30 \pm 0.02$ & $0.26 \pm 0.09$ & $0.40 \pm 0.13$ & $0.44 \pm 0.21$ \\
$5 \mathrm{~g}$ & $0.26 \pm 0.05$ & $0.32 \pm 0.02$ & $0.42 \pm 0.10$ & $0.33 \pm 0.05$ \\
\hline
\end{tabular}


Table 2. Summary results of ANOVAs on the interactive effect of nutrient enrichment ( 0 - $10 \mathrm{~g} \mathrm{NPK})$, salinity ( $0 \%$ - $100 \%$ seawater) and waterlogging on photosynthetic yield of $H$. littoralis seedlings.

\begin{tabular}{cccc}
\hline Source of variation & $F$ & $F$-crit & $P$-value \\
\hline Nutrient/SW0 & 5.5461 & 2.7826 & 0.002 \\
Nutrient/SW33 & 26.7944 & 2.7826 & 0.000 \\
Nutrient/SW66 & 12.7333 & 2.7826 & 0.000 \\
Nutrient/SW100 & 2.8171 & 2.7826 & 0.048 \\
Nutrient across salinities & 5.5856 & 2.6456 & 0.001 \\
\hline
\end{tabular}

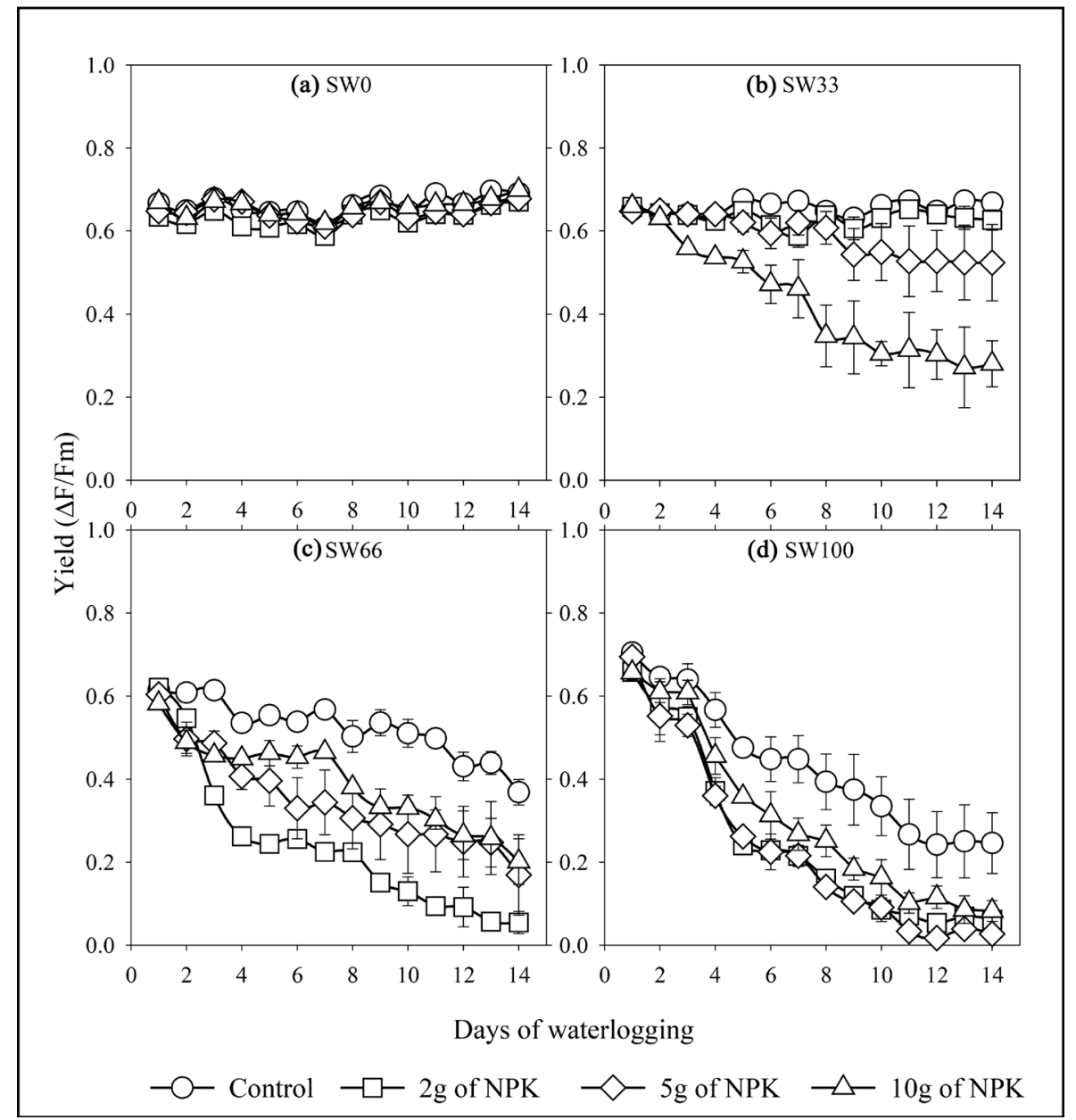

Figure 2. Photosynthetic yield (means $\pm 1 \mathrm{SE}, \mathrm{n}=30$ ) of $H$. littoralis seedlings in response to waterlogging, elevated salinity and nutrient enrichment.

effects of salinity and waterlogging, adding a compounding effect to decreased photosynthetic yield in the highest load of nutrient enrichment (Figure 2(b)). In elevated salinities of SW66 and SW100, all three stress factors: waterlogging, salinity and nutrient enrichment compounded to significantly decrease photosynthetic yield with the lowest levels observed in SW100 (Figure 2(c), Figure 2(d)).

\subsection{Leaf Chlorophyll Content}

Total Chl $(a+b)$ (Figure 3) and Chl $a / b$ ratios (Table 3) varied across salinity and nutrient levels. The lowest values of total Chl $(a+b)$ and Chl $a / b$ ratio were recorded in SW100, 10 g nutrient treatment. These Chl pattern support the declining photosynthetic yield performance with both increasing salinities and nutrient enrichment 
(Figure 2). The Chl $a / b$ ratio and photosynthetic yield were in overall found to have slight positive correlation of 0.3163 .
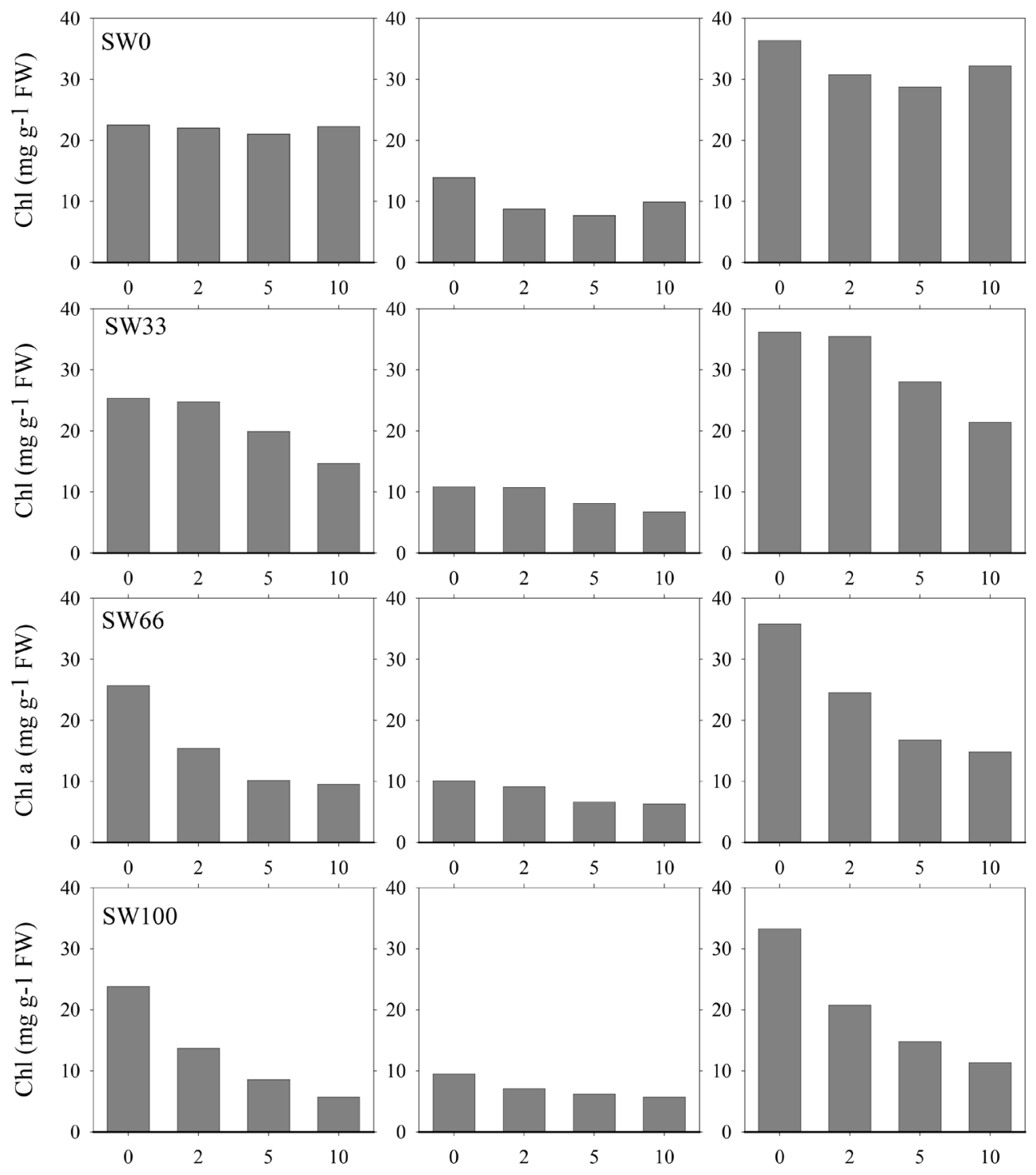

NPK nutrient loads $(\mathrm{g} /$ seedling)

Figure 3. Variation of leaf Chl content in response to nutrient enrichment with farm NPK (20:20:20) under interactive stress of salinity and waterlogging. FW is fresh weight, left column is Chl $a$, middle column is Chl $b$ and right column is Chl $a+b$.

Table 3. Variation of foliar $\mathrm{Chl} a / b$ ratios in response to nutrient enrichment under interactive stress of salinity and waterlogging.

\begin{tabular}{ccccc}
\hline NPK nutrient load & SW0 & SW33 & SW66 & SW100 \\
\hline Control & 1.622 & 2.333 & 2.543 & 2.509 \\
$2 \mathrm{~g}$ & 2.517 & 2.309 & 1.694 & 1.936 \\
$5 \mathrm{~g}$ & 2.728 & 2.455 & 1.533 & 1.385 \\
$10 \mathrm{~g}$ & 2.253 & 2.182 & 1.518 & 1.002 \\
\hline
\end{tabular}




\section{Discussion}

\subsection{Growth}

Results of this study show that nutrient enrichment did not enhance growth of seedlings, as a function of biomass accumulation. Mangrove seedlings had a significant shift of biomass to roots with increase in salinity, conflicting with advantageous availability of nutrients for shoot growth. [3] reported contrasting species specificity in response to interactive flooding, nutrient and salinity where, for example, $L$. racemosa recorded higher growth with shifts of biomass to shoots than roots compared to A. germinans and $R$. mangle which showed a reverse pattern when subjected to prolonged flooding.Higher biomass allocation to roots indicated that the seedlings are more tolerant to low nutrient condition in the presence of stress from other sediment factors of waterlogging and salinity. Enriching nutrients is expected to induce fast growth in shoots because plants tend to invest more in shoot development than roots [2] [23]. [24] reported that many of the traits that lead to fast growth under enhanced nutrient availability are not favourable under conditions of environmental stress. Enhanced growth is accompanied by other physiological changes like increased hydraulic conductivity and photosynthetic rates which are significantly influenced by salinity [23] [25].

These findings contrasts what [19] suggested that mangroves which were exposed to high nutrient availability, and had relatively lower capacity to invest in roots than shoots, suffered greater mortality when exposed to inundation and salinity stress. Here, plants invested in roots but still suffered greater mortality in elevated salinity and nutrients. Lack of variation within salinities with varied nutrient enrichment in the present study (Table 1) suggested that the would be benefits to increased seedling growth in response to nutrient addition was offset by salinity and exacerbated by waterlogging which lowered the plant growth. Possible inhibition of nutrient uptake and use in high salinity is reported from other wetland plants like the salt marshes [26].

\subsection{Photosynthesis}

The role of nutrient enrichment in enhancing photosynthesis was restricted by the increase in salinity (Figure 2). The antagonistic allocation of more biomass to roots than shoots, suggestively as a survival strategy in higher salinities occurred at the expense of leaf biomass, photosynthesis and thus growth by itself. [27] suggested that such biomass allocation pattern is the plant's strategy to meet higher requirements for water and nutrients in salinity stress. Even if nutrient supply is enhanced, [28] argued that the high cost of osmotic adjustment for nutrient absorption along the root-leaf column under high salinity cause nutrient deficiency in plant growth.

Under increasing nutrient availability (Figure 2), traits that confer enhanced photosynthetic rates and facilitate monopolization of nutrient resources lead to otherwise shoot weakness and thus the photosynthetic apparatus. [25] observed that in mangroves, photosynthetic efficiency in nutrient use per leaf nutrient content is high under limiting nutrients but [1] noted a contrasted decline in efficiency with increasing nutrient availability.

While total leaf Chl did not vary significantly, Chl $a / b$ ratio varied (Figure 3 and Table 3 ). Chl $a / b$ ratio is considered as an index of the light harvesting capability of chloroplasts [29]. Assuming Chl $a / b$ ratio of $\geq 3.0$ to reflect the normal composition of photosynthetic light-harvesting complexes and usual value in higher plants [30], the observed ratios represented deficiencies in photosynthesis as exemplified by the declined photosynthetic yield in higher salinity and nutrient levels (Figure 2). Low Chl $a / b$ ratios represent shade tolerance. That is, a typical shade adaptation is the increased levels of $\mathrm{Chl} b$ that permit more trapping of photons that are then transferred to Chl $a$ [29] [30]. The observed lower correlation coefficient between photosynthetic fluorescence and $\mathrm{Chl} a / b$ ratios indicated that there were factors other than functions of photosynthetic pigments that influence photosynthetic yield in stressful environmental conditions. Nonetheless, the ratio of Chl $a / b$ would still be however a good indicator of photosynthetic efficiency.

\subsection{Conclusion}

Waterlogging and salinity distracted biomass partitioning between the shoot and root and therefore growth. Nutrient enrichment depressed shoot formation in higher salinities, down regulating photosynthesis. Though the mechanism is not clear enough, the suppressing effect of increasing salinity on biomass allocation and the possible inhibition of nutrient uptake in high salinity are suggested to contribute to the inhibition effect on growth and photosynthesis in mangrove seedlings. The trade-offs between water balance, nutrient uptake and utilization and salt exclusion and tolerance, indicate that an understanding of the changes in biomass allocation alone may 
not necessarily explain the ecophysiology of mangrove plants stressed by salinity and inundation. Limitations from other environmental variables like nutrient additions and possibly eutrophication that often accompany terrestrial run-offs into estuaries considerably impose constraints to the growth media as well. This study concurs with a suggestion by [19] that long-term assessments on the consequences of nutrient enrichment in mangrove ecosystems are vital. Mangroves are widely being proposed as suitable for use in constructed wetlands to curb for sewage and aquaculture effluents [31]-[33], with enriching nutrients. So, where the succession niche is not able to cope with such environmental dynamics, the relevance of such management initiatives remains at stake. Choice of species is also a management aspect of consideration when strategizing on ecological use of mangroves.

\section{Acknowledgements}

This study was conducted with financial support from the Sida Bilateral Marine Science Programme implemented by the University of Dar es Salaam and Stockholm University.

\section{References}

[1] Feller, I.C., Whigham, D.F., McKee, K.L. and Lovelock, C.E. (2003) Nitrogen Limitation of Growth and Nutrient Dynamics in a Mangrove Forest, Indian River Lagoon, Florida. Oecologia, 134, 405-414. http://dx.doi.org/10.1007/s00442-002-1117-z

[2] Lovelock, C.E., Feller, I.C., McKee, K.L., Engelbrecht, B.M. and Ball, M.C. (2004) The Effect of Nutrient Enrichment on Growth, Photosynthesis and Hydraulic Conductance of Dwarf Mangroves in Panama. Functional Ecology, 18, 2533. http://dx.doi.org/10.1046/j.0269-8463.2004.00805.x

[3] Krauss, K.W., Doyle, T.W., Twilley, R.R., Rivera-Monroy, V.H. and Sullivan, J.K. (2006) Evaluating the Relative Contributions of Hydroperiod and Soil Fertility on Growth of South Florida Mangroves. Hydrobiologia, 569, 311-324. http://dx.doi.org/10.1007/s10750-006-0139-7

[4] López-Hoffman, L., DeNoyer, J.L., Monroe, I.E., Shaftel, R., Anten, N.P.R., Martínez-Ramos, M. and Ackerly, D.D. (2006) Mangrove Seedling Net Photosynthesis, Growth, and Survivorship Are Interactively Affected by Salinity and Light. Biotropica, 38, 606-616. http://dx.doi.org/10.1111/j.1744-7429.2006.00189.x

[5] Naidoo, G., Rogalla, H. and von Willert, D.J. (1997) Gas Exchange Responses of a Mangrove Species, Avicennia marina, to Waterlogged and Drained Conditions. Hydrobiologia, 352, 39-47. http://dx.doi.org/10.1023/A:1003088803335

[6] Chen, R. and Twilley, R.R. (1999) Patterns of Mangrove Forest Structure and Soil Nutrient Dynamics along the Shark River Estuary, Florida. Estuaries, 22, 955-970. http://dx.doi.org/10.2307/1353075

[7] Krauss, K.W., Lovelock, C.E., McKee, K.L., López-Hoffman, L., Ewe, S.M.L. and Sousa, W.P. (2008) Environmental Drivers in Mangrove Establishment and Early Development: A Review. Aquatic Botany, 89, 105-127. http://dx.doi.org/10.1016/j.aquabot.2007.12.014

[8] McLeod, E. and Salm, R.V. (2006) Managing Mangroves for Resilience to Climate Change. The International Union for the Conservation of Nature and Natural Resources (IUCN), Gland, Switzerland.

[9] Mangora, M.M., Mtolera, M.S.P. and Björk, M. (2014) Photosynthetic Responses to Submergence in Mangrove Seedlings. Marine and Freshwater Research, 65, 497-504. http://dx.doi.org/10.1071/MF13167

[10] Krauss, K.W. and Allen, J.A. (2003) Influences of Salinity and Shade on Seedling Photosynthesis and Growth of Two Mangrove Species, Rhizophora mangle and Bruguiera sexangula, Introduced to Hawaii. Aquatic Botany, 77, 311-324. http://dx.doi.org/10.1016/j.aquabot.2003.08.004

[11] Boto, K.G. and Wellington, J.T. (1983) Nitrogen and Phosphorus Nutritional Status of a Northern Australian Mangrove Forest. Marine Ecology Progress Series, 11, 63-69. http://dx.doi.org/10.3354/meps011063

[12] Naidoo, G. (1987) Effects of Salinity and Nitrogen on Growth and Relations in the Mangrove, Avicennia marina (Forsk.) Vierh. New Phytologist, 107, 317-325. http://dx.doi.org/10.1111/j.1469-8137.1987.tb00183.x

[13] Lin, G. and Sternberg, L.S.L. (1992) Effect of Growth Form, Salinity, Nutrient and Sulfide on Photosynthesis, Carbon Isotope Discrimination and Growth of Red Mangrove (Rhizophora mangle L.). Australian Journal of Plant Physiology, 19, 509-517. http://dx.doi.org/10.1071/PP9920509

[14] Koch, M.S. (1997) Rhizophora mangle L. Seedling Development into the Sapling Stage across Resource and Stress Gradients in Subtropical Florida. Biotropica, 29, 427-439. http://dx.doi.org/10.1111/j.1744-7429.1997.tb00037.x

[15] Feller, I.C., Whigham, D.F., McKee, K.L. and O’Neill, J.P. (2002) Nitrogen vs. Phosphorus Limitation across an Ecotonal Gradient in a Mangrove Forest. Biogeochemistry, 62, 145-175. http://dx.doi.org/10.1023/A:1021166010892 
[16] Lovelock, C.E., Feller, I.C., Ellis, J., Hancock, N., Schwarz, A.M. and Sorrell, B. (2007) Mangrove Growth in New Zealand Estuaries: The Role of Nutrient Enrichment at Sites with Contrasting Rates of Sedimentation. Oecologia, 153, 633-641. http://dx.doi.org/10.1007/s00442-007-0750-y

[17] Martin, K.C. (2007) Interactive Effects of Salinity and Nutrients on Mangrove Physiology: Implications for Mangrove Forest Structure and Function. PhD Thesis, Australian National University, Canberra.

[18] Tilman, D. (1991) Relative Growth Rate and Plant Allocation Patterns. The American Naturalist, 138, 1269-1275. http://dx.doi.org/10.1086/285283

[19] Lovelock, C.E., Ball, M.C., Martin, K.C. and Feller, I.C. (2009) Nutrient Enrichment Increases Mortality of Mangroves. PLoS ONE, 4, e5600. http://dx.doi.org/10.1371/journal.pone.0005600

[20] Ellis, J., Nicholls, P., Craggs, R., Hofstra, D. and Hewitt, J. (2004) Effects of Terrigenous Sedimentation on Mangrove Physiology and Associated Macrobenthic Communities. Marine Ecology Progress Series, 270, 71-82. http://dx.doi.org/10.3354/meps270071

[21] Genty, B., Briantais, J.M. and Baker, N.R. (1989) The Relationship between the Quantum Yield of Photosynthetic Electron Transport and Quenching of Chlorophyll Fluorescence. Biochimica et Biophysica Acta, 990, 87-92. http://dx.doi.org/10.1016/S0304-4165(89)80016-9

[22] Lichtenthaler, H.K. (1987) Chlorophylls and Carotenoids, the Pigments of Photosynthetic Biomembranes. In: Douce, R. and Packer, L., Eds., Methods in Enzymology, Academic Press Inc., New York, 350-382. http://dx.doi.org/10.1016/0076-6879(87)48036-1

[23] Naidoo, G. (2009) Differential Effects of Nitrogen and Phosphorus Enrichment on Growth of Dwarf Avicennia marina Mangroves. Aquatic Botany, 90, 184-190. http://dx.doi.org/10.1016/j.aquabot.2008.10.001

[24] Field, C., Merino, J. and Mooney, H.A. (1983) Compromises between Water-Use Efficiency and Nitrogen-Use Efficiency in 5 Species of California Evergreens. Oecologia, 60, 384-389. http://dx.doi.org/10.1007/BF00376856

[25] Youssef, T. and Saenger, P. (1996) Anatomical Adaptive Strategies to Flooding and Rhizosphere Oxidation in Mangrove Seedlings. Australian Journal of Botany, 44, 297-313. http://dx.doi.org/10.1071/BT9960297

[26] Bradley, P.M. and Morris, J.T. (1991) The Influence of Salinity on the Kinetics of $\mathrm{NH}_{4}$ Uptake in Spartina alterniflora. Oecologia, 85, 375-380. http://dx.doi.org/10.1007/BF00320613

[27] Boogaard, V.D., Goubitz, S., Veneklaas, E.J. and Lambers, H. (1996) Carbon and Nitrogen Economy of Four Triticum aestivum Cultivars Differing in Relative Growth Rate and Water Use Efficiency. Plant, Cell and Environment, 19, 998-1004. http://dx.doi.org/10.1111/j.1365-3040.1996.tb00465.x

[28] Kao, W.-Y., Tsai, H.-C. and Tsai, T.-T. (2001) Effect of NaCl and Nitrogen Availability on Growth and Photosynthesis of Seedlings of a Mangrove Species, Kandelia candel (L.) Druce. Journal of Plant Physiology, 158, 841-846. http://dx.doi.org/10.1078/0176-1617-00248

[29] Anderson, J.M., Chow, W.S. and Goodchild, D.C. (1988) Thylakoid Membrane Organization in Sun/Shade Acclimation. Australian Journal of Plant Physiology, 15, 11-26. http://dx.doi.org/10.1071/PP9880011

[30] Das, A.B., Parida, A., Basak, U.C. and Das, P. (2002) Studies on Pigments, Proteins and Photosynthetic Rates in Some Mangroves and Mangrove Associates from Bhitarkanika, Orissa. Marine Biology, 141, 415-422. http://dx.doi.org/10.1007/s00227-002-0847-0

[31] Clough, B.F., Boto, K.G. and Attiwill, P.M. (1983) Mangrove and Sewage: A Reevaluation. In: Teas, H.J., Ed., Biology and Ecology of Mangroves, Tasks for Vegetation Science Series, Vol. 8, Dr W Junk Publishers, Lancaster, 151-162. http://dx.doi.org/10.1007/978-94-017-0914-9_17

[32] Robertson, A.I. and Phillips, M.J. (1995) Mangroves as Filters of Shrimp Farm Effluent: Predictions and Biogeochemical Research Needs. Hydrobiologia, 295, 311-321. http://dx.doi.org/10.1007/BF00029138

[33] Wong, Y.S., Tam, N.F.Y. and Lan, C.Y. (1997) Mangrove Wetlands as Wastewater Treatment Facility: A Field Trial. Hydrobiologia, 352, 49-59. http://dx.doi.org/10.1023/A:1003040920173 